\title{
Effects of Circle of Willis Anatomic Variations on Angiographic and Clinical Outcomes of Coiled Anterior Communicating Artery Aneurysms
}

\author{
E. Tarulli, M. Sneade, A. Clarke, A.J. Molyneux, and A.J. Fox
}

\begin{abstract}
BACKGROUND AND PURPOSE: Anterior communicating artery aneurysms account for one-fourth of all intracranial aneurysms and frequently occur in the context of Al vessel asymmetry. The purpose of this study was to correlate circle of Willis anatomic variation association to angiographic and clinical outcomes of anterior communicating aneurysm coiling.
\end{abstract}

MATERIALS AND METHODS: The Cerecyte Coil Trial provides a subgroup of 124 cases with anterior communicating artery aneurysms after endovascular coiling. One hundred seventeen of 124 anterior communicating artery aneurysms had complete imaging and follow-up for clinical outcome analysis, stability of aneurysm coil packing, and follow-up imaging between 5 and 7 months after treatment. Clinical outcomes were assessed by the mRS at 6 months.

RESULTS: Anterior cerebral artery trunk-dominance was seen in 91 of $124(73 \%)$ anterior communicating artery aneurysms and codominance in 33 of $124(27 \%)$ anterior communicating artery aneurysms. There was no significant difference $(P>.5)$ in treatment success at 5-7 months for anterior communicating artery aneurysms between the anterior cerebral artery trunk-dominant (49 of 86, 57\%) and anterior cerebral artery trunk-codominant (19 of 31) groups. Angiographic follow-up demonstrates a statistically significant increase in neck remnants and progressive aneurysm sac filling with the Al dominant configuration ( $n=21,24 \%$ at follow-up versus $n=11,12 \%$ at immediate posttreatment, $P=.035$ ). There was no statistically significant difference in clinical outcomes between types of anterior cerebral artery trunk configuration $(P>.5)$.

CONCLUSIONS: Anterior communicating artery aneurysms with anterior cerebral artery trunk-dominant circle of Willis configurations show less angiographic stability at follow-up than those with anterior cerebral artery trunk-codominance similar to other "termination" type aneurysms. This supports the hypothesis that anterior cerebral artery trunk-dominant flow contributes to aneurysm formation, growth, and instability after coiling treatment.

ABBREVIATIONS: AcomA = anterior communicating artery; $\mathrm{A} 1=$ anterior cerebral artery trunk; $\mathrm{A} 2$ = pericallosal artery; $\mathrm{CCT}=\mathrm{Cerecyte}$ Coil Trial

$T^{T}$ he most common site of intracranial aneurysms is the anterior communicating artery (AcomA). AcomA aneurysms account for approximately one-fourth of all intracranial aneurysms. ${ }^{1}$ Also very common in the setting of AcomA aneurysms is unilateral anterior cerebral artery trunk (A1) dominance where 1 side supplies both pericallosal artery (A2) arteries, a well-known phenom-

Received January 2, 2014; accepted after revision January 9.

From the Department of Medical Imaging (E.T., A.J.F.), University of Toronto, Ontario, Canada; and Oxford Neurovascular and Neuroradiology Research Unit (M.S., A.C., A.J.M.), University of Oxford, Oxford, UK.

This work was supported by Sunnybrook Research Foundation through the Linda McCleod Memorial Fund and its founder Ouilla Shirriff, and by Micrus Endovascular Corporation, San Jose, California, providing funding as a trial sponsor.

Please address correspondence to Emidio Tarulli, MD, MHSc, Department of Medical Imaging, University of Toronto, Toronto, ON M5T 1W7, Canada; e-mail: e.tarulli@utoronto.ca

http://dx.doi.org/10.3174/ajnr.A3991 enon previously shown to be a potent risk factor for AcomA aneurysm formation and rupture. ${ }^{1-3}$

To what extent vessel dominance influences the long-term result of endovascular packing of these aneurysms with detachable platinum coils and the patients' clinical outcome is less well known. ${ }^{4-6}$ One previous study indicates that vessel dominance is not a major factor in predicting short-term treatment outcome; however, the methodology and definition of vessel dominance as used in this instance was not stated. ${ }^{7}$ Yet, anterior communicating aneurysms are commonly "termination type" with the aneurysm forming with a relatively wide neck at the site of the inferred jet of flowing blood dynamics, with main branches nearly perpendicular to the parent vessel, also commonly seen for basilar tip, internal carotid tip, and middle cerebral bifurcations. ${ }^{8}$

The Cerecyte Coil Trial (CCT) was a prospective, randomized, controlled study that entered 500 cases comparing endovascular coiling of ruptured and unruptured cerebral aneurysms with 


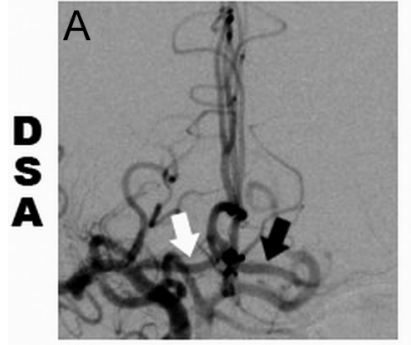

Co-Dominant

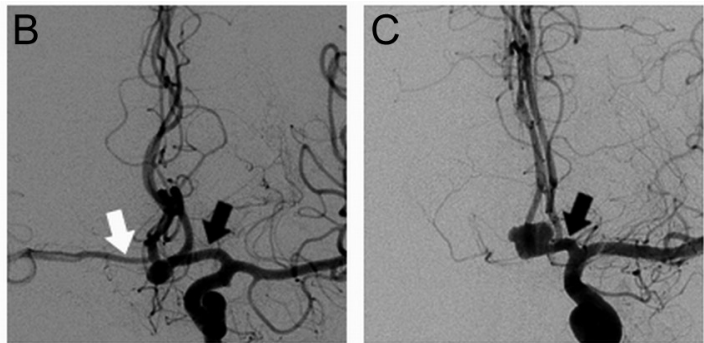

\section{Dominant}

FIG 1. DSA studies showing examples of $A 1$ segment categories with white and black arrows indicating right and left $A 1$, respectively, for codominant $(A)$ and dominant ( $B$ and $C$ ) configurations. Panels $B$ and $C$ demonstrate $A 1$ dominant cases with diminutive and absent contralateral $A 1$ segments, respectively.

either Cerecyte or bare platinum coils that showed no difference between groups. ${ }^{9,10}$ There was an expected large subset of AcomA aneurysms within the CCT cohort $(n=124) .{ }^{9}$ Therefore, data from this trial provided a unique opportunity to obtain a large number of AcomA aneurysm cases for determination of A1 dominance in relation to coiling treatment and angiographic outcomes immediately posttreatment and at follow-up. Our goal was to determine the impact of A1 dominance on treatment success, stability, and clinical outcomes of endovascularly coiled AcomA aneurysms.

\section{MATERIALS AND METHODS}

The methodology of the CCT core laboratory analysis of angiographic outcomes has been previously published with 249 and 251 aneurysm cases randomized and treated by bare platinum and Cerecyte coils. ${ }^{9}$ The CCT data base was made available for this analysis. All CCT cases were studied by selective DSA at the completion of coiling treatments and most follow-up imaging data were from selective catheter DSA and a few from CTA and MRA.

The CCT core laboratory data base has $n=124$ cases of AcomA aneurysms with copies of baseline imaging data pre- and postendovascular coiling available for determination of A1 dominance. Of these 124 AcomA cases, $n=117$ had complete follow-up imaging data at 5-7 months (7 cases with incomplete available data were omitted from assessment) and $n=86$ had follow-up data at 12-14 months. ${ }^{3}$ A subgroup of "termination type" aneurysms (basilar tip and MCA) was used for comparison with $n=89$ cases at baseline and $n=78$ at 5-7 month follow-up.

A1 vessel dominance of either anterior cerebral artery trunk supplying both pericallosal arteries was determined by the combined anatomic and flow dilution method illustrated in Fig 1 as previously shown. ${ }^{3}$ This allowed division of the AcomA aneurysm group into 2 groups: A1 codominant and A1 dominant. In the A1 codominant group, there was no clear dominance of the inflow contribution of one A1 segment over the other. If flow data were not available, the A1 codominance was determined if diameter of Al (large) $\leq 2 \times \mathrm{A} 1$ (small). In the A1 dominant group, there was clearly more contribution of flow from one Al segment to the distal A2 segments than the contralateral A1 segment, or no detectable inflow contribution from the contralateral A1 segment. If flow data were not available, A1 dominance was classified when A1 (large) $\geq 2 \times$ A1 (small) or A1 (small) was not apparent or detectable on the available imaging.
Angiographic appearance at the end of endovascular procedure was considered as baseline for this analysis and the degree of aneurysm occlusion was categorized as complete, neck remnant, sac filling/incomplete, and overlapping coils/neck as determined by the CCT core laboratory. ${ }^{9,11}$

To be consistent with prior publications that did not recognize the difference between presumed complete occlusion and overlapping coils/neck, and to facilitate comparison between baseline and follow-up angiographic appearance, overlapping coils/neck was combined with complete occlusion, and no change at follow-up was assigned to the postembolization category. ${ }^{8,11}$ Cases with incomplete angiographic data or no follow-up data were excluded from this analysis.

The follow-up images between 5 and 7 months were analyzed with reference to the initial posttreatment angiogram. The CCT core laboratory determined angiographic treatment success at 5-7 months by comparison with the initial degree of occlusion on the posttreatment angiogram as complete, improved, or not changed (for example: stable neck remnant) in appearance from baseline. Clinical outcomes were assessed by the mRS at 6 months as collected by the CCT Coordinating Centre through Web-based forms and previously published. ${ }^{10}$

Statistical comparisons were made both within and between groups using the Fisher exact test or $\chi^{2}$ test with a 2 -sided $P$ value of .05, as appropriate. McNemar and Stuart-Maxwell tests for marginal homogeneity were applied to baseline and 5-7 month follow-up to determine the proportion of change in angiographic case classification over time. ${ }^{12}$

\section{RESULTS}

Table 1 summarizes angiographic outcomes at the end of the coiling procedures and at 5-7 month follow-up for the Al subgroups and "termination" aneurysms. A1 dominance was seen in $73 \%$ $(n=91)$ of AcomA aneurysms and $27 \%(n=33)$ of A1 codominant. Postcoiling sac filling was seen in similar proportions in both groups at baseline and at 5-7 month follow-up. There were 7 patients who had required retreatment (1 A1-codominant, 6 A1dominant), and 1 of the patients who was A1-dominant had retreatment after re-bleed. At 12-14 month follow-up, 86 of 117 cases from the 5-7 month follow-up had complete follow-up data. The proportion of A1 codominant aneurysms with sac filling remained stable at $23 \%(n=7)$ while the $\mathrm{A} 1$ dominant group increased to $30 \%(n=18)$. The "termination" aneurysm group had a significant increase in neck remnants from 29 to 41 (33\% to $53 \%)$.

Table 2 presents the CCT definition of success for A1 dominant and codominant AcomA aneurysms; $57 \%(n=49$ of 86$)$ of A1-dominant AcomA aneurysms and 61\% $(n=19$ of 31$)$ of A1codominant AcomA aneurysms were deemed successfully treated. The Fisher exact test showed no statistical significance in 


\begin{tabular}{|c|c|c|c|c|c|c|}
\hline \multirow[b]{2}{*}{$\begin{array}{l}\text { Angiographic } \\
\text { Occlusion }\end{array}$} & \multicolumn{3}{|c|}{ Baseline Post-Coiling } & \multicolumn{3}{|c|}{ 5-7 Month Follow-Up } \\
\hline & $\begin{array}{c}\text { AcomA } \\
\text { Aneurysm A1 } \\
\text { Codominant } \\
(n=33), \\
\text { No. }(\%)\end{array}$ & $\begin{array}{c}\text { AcomA } \\
\text { Aneurysm A1 } \\
\text { Dominant } \\
(n=91), \\
\text { No. }(\%)\end{array}$ & $\begin{array}{c}\text { Basilar/MCA } \\
\text { Termination } \\
\text { Aneurysms } \\
(n=89) \\
\text { No. }(\%)\end{array}$ & $\begin{array}{c}\text { AcomA } \\
\text { Aneurysm A1 } \\
\text { Codominant } \\
(n=31), \\
\text { No. }(\%)\end{array}$ & $\begin{array}{c}\text { AcomA } \\
\text { Aneurysm A1 } \\
\text { Dominant } \\
(n=86), \\
\text { No. (\%) }\end{array}$ & $\begin{array}{c}\text { Basilar/MCA } \\
\text { Termination } \\
\text { Aneurysms } \\
(n=78), \\
\text { No. }(\%)\end{array}$ \\
\hline Complete & $12(36 \%)$ & $48(53 \%)$ & $45(50 \%)$ & $13(42 \%)$ & $34(40 \%)$ & $22(28 \%)$ \\
\hline Neck remnant & $16(49 \%)$ & $32(35 \%)$ & $29(33 \%)$ & $11(35 \%)$ & $31(36 \%)$ & $41(53 \%)$ \\
\hline Sac filling & $5(15 \%)$ & $11(12 \%)$ & 15 (17\%) & $7(23 \%)$ & $21(24 \%)$ & 15 (19\%) \\
\hline
\end{tabular}

Table 2: CCT definition of success at 5-7 months

\begin{tabular}{|c|c|c|}
\hline $\begin{array}{l}\text { Angiographic } \\
\text { Occlusion at } \\
\text { First Follow-Up }\end{array}$ & $\begin{array}{c}\text { AcomA } \\
\text { Aneurysm A1 } \\
\text { Co-Dominant } \\
(n=31), \\
\text { No. }(\%)\end{array}$ & $\begin{array}{c}\text { AcomA } \\
\text { Aneurysm A1 } \\
\text { Dominant } \\
(n=86), \\
\text { No. (\%) }\end{array}$ \\
\hline Complete & $13(42 \%)$ & $29(34 \%)$ \\
\hline Stable & $0(0 \%)$ & $3(3 \%)$ \\
\hline Improved & $6(19 \%)$ & $17(20 \%)$ \\
\hline Total $^{\mathrm{a}}$ & $19(61 \%)$ & 49 (57\%) \\
\hline
\end{tabular}

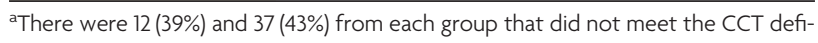
nition of success at 5-7 month follow-up.

Table 3: Change in angiographic appearance from baseline to first follow-up

\begin{tabular}{|c|c|c|c|}
\hline & \multicolumn{3}{|c|}{ Baseline $\left(n=31^{\mathrm{a}}\right)$} \\
\hline & $\begin{array}{c}\text { Complete } \\
\qquad(n=12)\end{array}$ & $\begin{array}{c}\text { Neck } \\
\text { Remnant } \\
(n=15)\end{array}$ & $\begin{array}{l}\text { Sac Filling } \\
(n=4)\end{array}$ \\
\hline \multicolumn{3}{|l|}{ First follow-up ( $n=31)$} & \\
\hline Complete $(n=13)$ & 9 & 4 & 0 \\
\hline Neck remnant $(n=11)$ & 1 & 9 & 1 \\
\hline \multirow[t]{3}{*}{ Sac filling $(n=7)$} & 2 & 2 & 3 \\
\hline & \multicolumn{3}{|c|}{ Baseline $\left(n=86^{\mathrm{a}}\right)$} \\
\hline & $\begin{array}{c}\text { Complete } \\
(n=47)\end{array}$ & $\begin{array}{c}\text { Neck } \\
\text { Remnant } \\
(n=30)\end{array}$ & $\begin{array}{c}\text { Sac Filling } \\
(n=9)\end{array}$ \\
\hline \multicolumn{4}{|l|}{ Al Dominant } \\
\hline Complete $(n=34)$ & 26 & 7 & 1 \\
\hline Neck remnant $(n=31)$ & 8 & 18 & 5 \\
\hline Sac filling $(n=21)$ & 13 & 5 & 3 \\
\hline
\end{tabular}

${ }^{a}$ Only baseline cases with follow-up data were included (31 of 33 and 86 of 91).

treatment success as defined between A1-dominant and codominant AcomA aneurysms $(P=.8)$.

Angiographic follow-up demonstrates a statistically significant increase in progressive aneurysm sac filling of initially incompletely coiled AcomA aneurysms with A1 dominant configuration ( $n=21,24 \%$ at follow-up versus $n=11,12 \%$ at immediate posttreatment, $P=.035$ ) and similarly a significant increase in neck remnants in the "termination" aneuryms group $(P=.01)$.

McNemar and Stuart-Maxwell tests were applied to paired baseline and 5-7 month follow-up angiographic classification (Table 3). The A1-dominant AcomA aneurysm group showed significant change in angiographic classification $(P=.03)$ and an increase in the proportion of cases with aneurysm sac filling $(P=.01)$. The same tests applied to the A1 codominant group were not significant.

There was no difference found in clinical outcomes between cases of AcomA aneurysms with A1 dominant and codominant configurations as quantified by the mRS applying the Fisher exact test consistent with the CCT trial as published previously. ${ }^{9,10}$

\section{DISCUSSION}

A1 dominance of one or another of the anterior cerebral artery trunks supplying both pericallosal arteries has previously been shown to be a significant risk factor for AcomA aneurysm incidence. ${ }^{1-3}$ There have been several hypotheses posed to explain the role of this observation in the formation of aneurysms of the AcomA artery region. Factors such as vessel wall shear stress, A1-A2 bifurcation angles, and flow patterns all depend intimately on the vessel geometry ${ }^{1,4,13}$ and likely contribute to aneurysm formation. However, the influence of A1 dominance on the angiographic and clinical outcomes of endovascularly coiled AcomA aneurysms has not been extensively studied. ${ }^{4-6}$ A previous study concluded that vessel dominance is not a major factor in predicting immediate postcoiling success; however, no long-term outcome assessments were available and both methodology and consistent definition of vessel dominance were not stated. ${ }^{7}$ Another study on the impact of morphologic features on 32 cases of endovascularly coiled AcomA aneurysms did not include A1 dominance as a factor but did conclude superiorly oriented aneurysm domes are more likely to be incompletely occluded postcoiling. ${ }^{14}$ More recently, a single-center multivariate retrospective analysis of the impact of morphologic factors on initial occlusion and long-term follow-up of 96 cases of AcomA aneurysms demonstrated A1 dominance and dome orientation as being most contributory to predicting the endovascular coiling outcome. ${ }^{15}$ Aneurysm orientation was not studied for this analysis given most of the data came from orthogonal DSA images that precluded measurement of true 3D orientation angles.

A recent meta-analysis of endovascular coiling outcomes of AcomA aneurysms reported overall immediate posttreatment rates of "complete and near complete occlusions" at $88 \%$ and long-term follow-up (at least 6 months) at $85 \% .{ }^{16}$ If the same definition were applied to our study, combining complete and neck remnants to be equivalent to "complete and near complete occlusions," the immediate postcoiling success rates are comparable at $85 \%$ and $88 \%$ for the $\mathrm{A} 1$ codominant and A1 dominant AcomA aneurysms, respectively. At the follow-up, however, this drops to $77 \%$ and $76 \%$, and applying the CCT trial definition of success at follow-up, the rate further reduces to $57 \%$ and $61 \%$. These discrepancies can be interpreted in several ways; however, the most important factor clearly lies in the angiographic interpretation. An independent study on the differences between the angiographic classifications reported by the operators versus the independent core laboratory reader found a 2 -fold difference in 


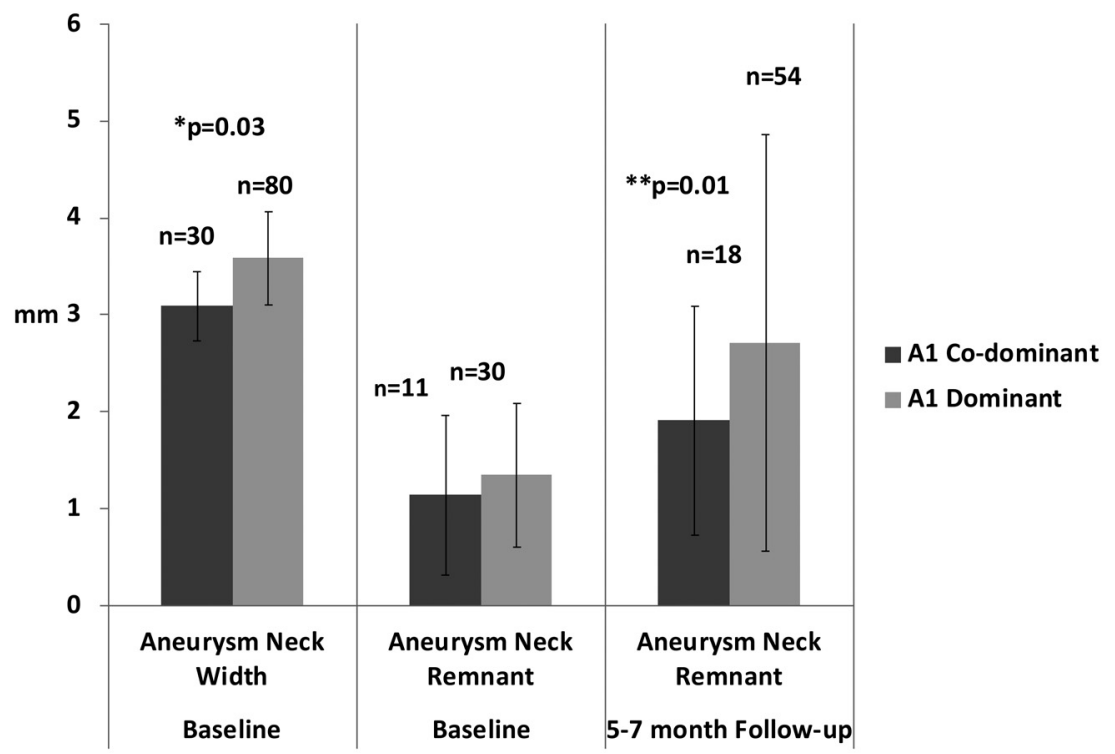

FIG 2. Anatomic dimensions of aneurysm neck width and remnants taken at baseline and follow-up imaging. All cases with available measurements in each group were included regardless of angiographic classification as listed in Table 1. The Al-dominant AcomA aneurysm group had a larger mean neck width at baseline and more variance in neck remnant at follow-up, $P=.03$ and .01 by ${ }^{*} t$ test and ${ }^{* *} F$ test, respectively.

the rate of reporting an unfavorable angiographic outcome. ${ }^{11}$ This factor alone could explain the differences between our study and the recent meta-analysis by Fang et al. ${ }^{16}$ Interestingly, the largest sources of data heterogeneity cited in the meta-analysis were angiographic outcomes immediately after coiling and in long-term follow-up.

Inherent to any subanalysis are the limitations of smaller numbers of cases within the subgroups. With 91 and 33 cases of AcomA aneurysms with A1 dominant and codominant configurations, respectively, the ability to detect small differences in outcomes comparing the groups directly is statistically underpowered. However, the significant results we present are highlighting the temporal changes of angiographic appearance as a marker of treatment stability within the same group.

Specifically, the A1 dominant group of coiled AcomA aneurysms showed angiographic instability over time with significant increase in cases with sac filling between baseline and follow-up time points ( 12 to $24 \%-30 \%$ ).

This suggests that endovascularly coiled A1 dominant AcomA aneurysms may be less stable. The A1 codominant group provides an important comparison: It has significant flow from both A1 vessels into the AcomA aneurysm and beyond to the A2 vessels. Therefore, one can postulate that in this situation there may not be a single jet of blood flowing directly into the aneurysm or neck remnant, pushing down on the coils and expanding the aneurysm over time. This phenomenon has been studied more extensively with computational flow dynamics of MCA "termination" type aneurysms, and similar concepts may apply here as well. ${ }^{17}$

Most the flow originates from a single vessel in the A1-dominant group, and compared with A1 codominant aneurysms, the aneurysm neck widths are significantly larger and both the size and variation of neck remnants on follow-up imaging are larger (Fig 2). This further supports the hypothesis that large jets of blood directed to 1 spot at a bifurcation leads to formation of a termination aneurysm predisposed to stretching, and, after coiling, to molding and flattening of coil masses. This would result in more remnants and sac filling.

The recently introduced of flow diverters and woven intrasaccular devices are interesting endovascular solutions that aim to prevent blood flow from entering the aneurysm thereby removing the source of the problem. ${ }^{18-21}$ Perhaps patients with A1-dominant AcomA aneurysms are a subgroup that might particularly benefit from treatment with such novel devices if they could be developed to maneuver through the sharp angles and small A1 artery.

\section{CONCLUSIONS}

AcomA aneurysms with A1-dominant circle of Willis configurations (one A1 supplying both A2 arteries) with incomplete occlusion at baseline may be less stable at follow-up than A1 codominant AcomA aneurysms, similar to other "termination" type aneurysms such as basilar tip and MCA bifurcation. This supports the hypothesis that A1-dominant flow contributes to AcomA aneurysm formation, growth, and instability of treatment by coiling.

\section{ACKNOWLEDGMENTS}

The authors thank the Sunnybrook Research Foundation for their generous support of this project through the Linda McCleod Memorial Fund and its founder Ouilla Shirriff.

Disclosures: Emidio Tarulli-RELATED: Support for Travel to Meetings for the Study or Other Purposes: Sunnybrook Research Foundation, Comments: Support to attend and present at ASNR 2013 meeting. Mary Sneade-RELATED: Support for Travel to Meetings for the Study or Other Purposes: Micrus Endovascular,* Comments: Received travel/accommodation suport from Micrus for Cerecyte Coil Trial site visits as part of the study protocol and meetings for the study setup and data presentation. Andy J. Molyneux-UNRELATED: Consultancy: Sequent Medical, Comments: Unrelated consulting and case adjudication. Allan Fox-RELATED: Grant: Micrus Corp, ${ }^{*}$ Comments: Case material for this study was derived from data of the Cerecyte Coil Trial. *Money paid to institution.

\section{REFERENCES}

1. Castro MA, Putman CM, Sheridan MJ, et al. Hemodynamic patterns of anterior communicating artery aneurysms: a possible association with rupture. AJNR Am J Neuroradiol 2009;30:297-302

2. De Rooij NK, Velthuis BK, Algra A, et al. Configuration of the circle of Willis, direction of flow, and shape of the aneurysm as risk factors for rupture of intracranial aneurysms. J Neurol 2009;256:45-50

3. Tarulli E, Fox AJ. Potent risk factor for aneurysm formation: termination aneurysms of the anterior communicating artery and detection of A1 vessel asymmetry by flow dilution. AJNR Am J Neuroradiol 2010;31:1186-91

4. Alnaes MS, Isaksen J, Mardal KA, et al. Computation of hemodynamics in the circle of Willis. Stroke 2007;38:2500-05

5. Wiebers DO, Whisnant JP, Huston J III, et al. Unruptured intracranial aneurysms: natural history, clinical outcome, and risks of surgical and endovascular treatment. Lancet 2003;362:103-10 
6. van der Schaaf I, Algra A, Wermer M, et al. Endovascular coiling versus neurosurgical clipping for patients with aneurysmal subarachnoid haemorrhage. Cochrane Database Syst Rev 2005;4:CD003085

7. Gonzalez N, Sedrak M, Martin N, et al. Impact of anatomic features in the endovascular embolization of 181 anterior communicating artery aneurysms. Stroke 2008;39:2776-82

8. Osborn AG. Diagnostic Cerebral Angiography. Philadelphia: Lippincott Williams \& Wilkins; 1999:241-55

9. Molyneux AJ, Clarke A, Sneade M, et al. Cerecyte coil trial: angiographic outcomes of a prospective randomized trial comparing endovascular coiling of cerebral aneurysms with either Cerecyte or bare platinum coils. Stroke 2012;43:2544-50

10. Coley S, Sneade M, Clarke A, et al. Cerecyte coil trial: procedural safety and clinical outcomes in patients with ruptured and unruptured intracranial aneurysms. AJNR Am J Neuroradiol 2012;33: 474-80

11. Rezek I, Lingineni R, Sneade M, et al. Differences in the angiographic evaluation of coiled cerebral aneurysms between a core laboratory reader and operators: results of the Cerecyte coil trial. AJNR Am J Neuroradiol 2014;35:124-27

12. Twisk JWR. Categorical and "count" outcome variables. Applied Longitudinal Data Analysis for Epidemiology. Cambridge, UK: Cambridge University Press; 2013:141-62

13. Kasuya H, Shimizu T, Nakaya K, et al. Angles between A1 and A2 segments of the anterior cerebral artery visualized by three-dimensional computed tomographic angiography and association of anterior communicating artery aneurysms. Neurosurgery 1999;45:8993; discussion 93-94
14. Uemura A, Kamo M, Matsukawa H. Angiographic outcome after endovascular therapy for anterior communicating artery aneurysms: correlation with vascular morphological features. Jpn J Radiol 2012;30:624-27

15. Songsaeng D, Geibprasert S, ter Brugge KG, et al. Impact of individual intracranial arterial aneurysm morphology on initial obliteration and recurrence rates of endovascular treatments: a multivariate analysis. J Neurosurg 2011;114:994-1002

16. Fang S, Brinjikji W, Murad MH, et al. Endovascular treatment of anterior communicating artery aneurysms: a systematic review and meta-analysis. AJNR Am J Neuroradiol 2014;35:943-47

17. Valen-Sendstad K, Steinman DA. Mind the gap: impact of computational fluid dynamics solution strategy on prediction of intracranial aneurysm hemodynamics and rupture status indicators. $A J N R$ Am J Neuroradiol 2014;35:536-43

18. Pierot L, Liebig T, Sychra V, et al. Intrasaccular flow-disruption treatment of intracranial aneurysms: preliminary results of a multicenter clinical study. AJNR Am J Neuroradiol 2012;33:1232-38

19. Pierot L, Klisch J, Cognard C, et al. Endovascular WEB flow disruption in middle cerebral artery aneurysms: preliminary feasibility, clinical, and anatomical results in a multicenter study. Neurosurgery 2013;73:27-34; discussion 34-35

20. Gross BA, Frerichs KU. Stent usage in the treatment of intracranial aneurysms: past, present and future. J Neurol Neurosurg Psychiatry 2013;84:244-53

21. Piano M, Valvassori L, Quilici L, et al. Midterm and long-term follow-up of cerebral aneurysms treated with flow diverter devices: a single-center experience. J Neurosurg 2013;118:408-16 